\title{
About the Editor
}

\section{David Monchaud}

David Monchaud received his PhD in organic chemistry in 2002 at the University of Geneva (Switzerland) with Jérôme Lacour. After a first postdoctoral experience in medicinal chemistry with Bernard P Roques (Paris, France), he joined the group of Jean-Marie Lehn at the College de France (Paris, France) for a second postdoctoral experience. He worked under the supervision of Marie-Paule Teulade-Fichou on G-quadruplex ligands; he was then appointed as CNRS researcher and moved with MP TeuladeFichou to the Institut Curie (Orsay, France) to develop an interdisciplinary chemistry related to quadruplex-DNA. Recently, he joined the Institute of Molecular Chemistry (ICMUB, Dijon, France) to lead a chemical biology unit in which he still expands the scope of nucleic acids-oriented projects, from therapeutic to nanotechnological applications.

For reprint orders, please contact reprints@future-science.com 


\section{Foreword}

\section{Biological relevance and}

therapeutic applications of DNA- and

\section{RNA-quadruplexes: double helix versus} quadruple helix

\section{David Monchaud}

The legendary events that swirl around DNA are among the most fascinating stories of the modern era of science. The wartime discovery that DNA might serve as a valuable therapeutic anticancer target was shrouded in the secrecy of chemical warfare and unethical investigations; soon afterwards, the precise elucidation of its molecular structure was pervaded by controversy, personality clashes and warring academic egos. DNA thus crystallizes the researchers' interest and passion for more than 60 years now. Coincidentally or not, the exact year of the sixtieth anniversary of the landmark Nature articles form Watson, Crick, Wilkins and Franklin on the DNA double helix, a long 15-year quest finally provided solid and reliable evidences that DNA can adopt in cells an alternative secondary architecture: a structure that deviates from the canonical duplex-DNA model in that it comprises not two but four self-assembled DNA strands, thus forming a quadruple helix more frequently referred to as quadruplex-DNA. The present book might thus have been entitled 'Quadruple Helix' to echo the 1968 'Double Helix' from JD Watson; the more accurate 'Biological relevance and therapeutic applications of DNA- and RNA-quadruplexes' was preferred since this book encompasses many technical facets of this nearly two decade-scientific adventure, each of them being discussed by eminent researchers from the field. Our wish is actually twofold: first, to address the simplest but crucial issues that will help the reader to enter this highly exciting field: what is a quadruplex (Chapter 1)? What does it look like, and what is the influence of the environment on their topological plurality (Chapters 2 and 3)? Where 
does it form and for which biological dividends (Chapters 4 and 5)? Second, to provide a precise roadmap that will enable the reader to precisely fathom the ins and outs of this rapidly evolving research area: is there any enzymatic regulation to mold or process them in cells (Chapters 6 and 7)? Why are quadruplexes considered as molecular switches at cellular level, and what roles do they play in the regulation of gene expression at both DNA and RNA levels (Chapters 8 and 9)? A special emphasis is also given to their unique position as a strategic linchpin for targeted anticancer therapies, enlightening the devised strategies to design small molecules that selectivity interact with quadruplexes, not only for therapeutic purposes but also for gaining insights into their in vivo relevance (Chapters 10-15). Our goal is thus to portray the quadruplex research field with its true colors, ending with a foray into DNA nanotechnologies (Chapter 16), which is becoming an increasingly important actor of the quadruplex field. We wish to highlight the forces and weaknesses of the quadruplex-related researches, their hard-won achievements and remaining challenges, in a concise but complete manner. May the reading of this book prompt many new researchers to embrace this thrill-packed, ever-renewed scientific adventure.

Acknowledgement

I would like to express my sincere gratitude to all authors for devoting their invaluable time to contribute to this book and make it a great moment of science. I am also indebted to Ryan De Vooght-Johnson, Naila Zaman and the entire editorial team at Future Science, for their precious assistance. Finally, I would like to thank all the people involved in the quadruplex field - particularly those I had the chance to work with or to meet over the past years - colleagues and friends worldwide, to make this field a fascinating, at times difficult, but always rewarding and stimulating scientific quest.

\section{Financial \& competing interests disclosure}

The author has no relevant affiliations or financial involvement with any organization or entity with a financial interest in or financial conflict with the subject matter or materials discussed in the manuscript. This includes employment, consultancies, honoraria, stock ownership or options, expert testimony, grants or patents received or pending, or royalties.

No writing assistance was utilized in the production of this manuscript. 